\title{
POSTERIOR CAPSULE OPACIFICATION FOLLOWING DIABETIC EXTRACAPSULAR CATARACT EXTRACTION
}

\author{
A. IONIDES, J. G. F. DOWLER, P. G. HYKIN, P. H. ROSEN and A. M. HAMILTON \\ London
}

\begin{abstract}
SUMMARY
Review was performed of extracapsular cataract extraction with posterior chamber lens implantation in 90 diabetic patients and 263 non-diabetic patients. There was a higher incidence of posterior capsular opacification as judged by the requirement for Nd:YAG posterior capsulotomy in patients with non-proliferative $(12 / 35,34 \%)$ or quiescent proliferative diabetic retinopathy $(8 / 18,44 \%)$ than in non-diabetic patients $(48 / 263,18 \%)$ (MantelHaenszel $p=0.04$ ). Although subgroup analysis showed a higher incidence of posterior capsule opacification in diabetics with non-proliferative or quiescent proliferative retinopathy than in diabetics without retinopathy, this was not statistically significant (Mantel-Haenszel $p=0.19$ and $p=0.07$, respectively). Following cataract surgery in diabetics with retinopathy, frequent review and prompt management of posterior capsular opacification is recommended, to maintain adequate fundus visualisation at a time when deterioration of retinopathy is likely.
\end{abstract}

Preservation of the posterior capsule during extracapsular cataract extraction retains an avascular membrane between the vitreous cavity and the anterior chamber of the eye. Maintenance of the integrity of the posterior capsule and anterior hyaloid face reduces the risk of retinal detachment ${ }^{1}$ and pseudophakic macular oedema, ${ }^{2}$ and is the major advantage of extracapsular over intracapsular cataract extraction. However, posterior capsule opacification is a frequent cause of visual impairment following extracapsular cataract surgery. This is an important complication in diabetics, in whom adequate fundus visualisation must be maintained because post-operative deterioration of retinopathy is likely.

Posterior capsular opacification is an age-related phenomenon and its incidence approaches $100 \%$ in paediatric cases. ${ }^{3.4}$ In the normal adult population the incidence is reported to the between $30 \%$ and $50 \%$ at 5 years. ${ }^{5.6} \mathrm{Fac}-$ tors believed to predispose to posterior capsular opac-

Correspondence to: J. G. F. Dowler, FRCS, FRCOphth, Moorfields Eye Hospital, City Road, London ECIV 2PD. UK. ification include complicated or traumatic surgery, incomplete removal of cortical lens matter, ${ }^{7}$ post-operative uveitis, and a plano posterior lens implant surface. ${ }^{7.8}$ Factors thought to reduce the incidence include a wide anterior capsulectomy ${ }^{9}$ and a posteriorly convex posterior chamber intraocular lens which is in close apposition to the posterior capsule and prevents migration of lens epithelial cells across the visual axis.

Cataract occurs at a younger age, ${ }^{10}$ and post-operative inflammation is typically more severe, ${ }^{11-14}$ in diabetics than in non-diabetics, suggesting that the incidence of posterior capsule opacification might be higher in diabetics, although a higher incidence in non-diabetics than diabetics has been reported. ${ }^{15}$ To investigate this further we reviewed our experience of posterior capsular opacification following diabetic cataract extraction.

\section{METHOD}

A retrospective review was performed of all diabetic and non-diabetic patients who underwent extracapsular cataract extraction and posterior chamber lens implantation during a 12 month period in 1990-1. Patients were excluded who had (1) a history of uveitis, (2) other proliferative retinopathy such as ischaemic central retinal vein occlusion, (3) coexisting retinal disease such as agerelated macular degeneration, (4) major operative complications such as vitreous loss, or (5) advanced diabetic eye disease including active proliferative diabetic retinopathy, iris neovascularisation and traction retinal detachment.

Pre-operative retinopathy severity was classified, as close to surgery as cataract allowed, into one of three groups: (1) no diabetic retinopathy, (2) non-proliferative diabetic retinopathy or (3) quiescent proliferative retinopathy defined as retinal neovascularisation managed by panretinal photocoagulation which had regressed with no further neovascularisation at 6 months follow-up.

Operations were performed by one consultant (A.M.H.) or experienced residents attached to this service. A corneal section was performed in the majority of cases. 'Canopener' anterior capsulotomy preceded expression of the 
nucleus with two-point pressure at 6 and 12 o'clock. Soft lens matter was aspirated with a coaxial cannula and a posterior chamber lens inserted under a viscous agent. The section was closed using interrupted 10.0 monofilament nylon sutures.

Patients were reviewed on the first post-operative day, at 2 weeks, at 10 weeks and at intervals up to a mean follow-up of 15 months (range 3-48 months). The presence of post-operative complications including uveitis, raised intraocular pressure, pigment dispersion and posterior synechiae was noted. If posterior capsular opacification was sufficient to cause reduced visual acuity or to impair adequate visualisation of the fundus, it was recorded and Nd:YAG capsulotomy was performed. All pre-operative and post-operative assessments were performed at Moorfields Eye Hospital and documentation was considered to be of good quality.

The incidence of posterior capsulotomy was modelled using Kaplan-Meier survival analysis to allow for variation in follow-up between groups. The survival of different groups was compared using the Mantel-Haenszel test. Cox's proportional hazards regression was used to compare survival in different groups controlling for covariates. The Wilcoxon rank sum test was used to compare medians in unpaired samples.

\section{RESULTS}

Ninety diabetic and 263 uncomplicated extracapsular cataract extractions with posterior chamber lens implantation were included in the study. Median age at surgery was 69 years in diabetics and 74 years in non-diabetics (Wilcoxon rank sum $p<0.05$ ). Capsulotomy was undertaken in 48 of $263(18 \%)$ non-diabetics, 5 of 37 (14\%) diabetics without retinopathy, 12 of 35 (34\%) diabetics with non-proliferative retinopathy, and 8 of 18 (44\%) diabetics with quiescent proliferative retinopathy.

There was a higher incidence of posterior capsular opacification as judged by the requirement of $\mathrm{Nd}: \mathrm{YAG}$ capsulotomy in diabetics with non-proliferative (12/35, $34 \%)$ or quiescent proliferative diabetic retinopathy $(8 / 18$, $44 \%)$ than in non-diabetics (18\%) (Mantel-Haenszel $p=0.04$; Fig. 1). Subgroup analysis showed a higher

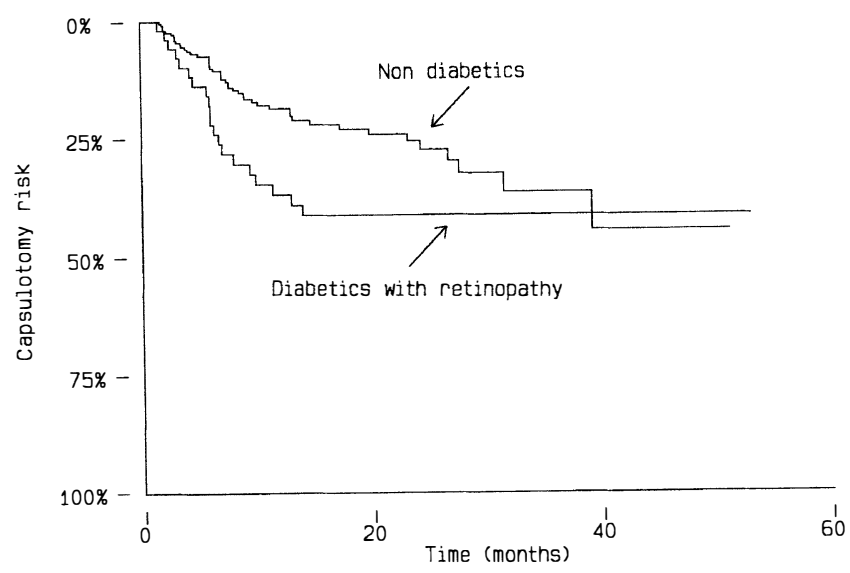

Fig. 1. Kaplan-Meier survival curve showing capsulotomy risk in diabetics with retinopathy and in non-diabetic's. incidence of capsular opacification in diabetics with nonproliferative $(12 / 35,34 \%)$ or quiescent proliferative retinopathy $(8 / 18,44 \%)$ than in diabetics without retinopathy $(5 / 37,14 \%)$, but this was not statistically significant (Mantel-Haenszel $p=0.19$ and $p=0.07$, respectively; Fig. 2). There was no overall difference in the incidence of capsular opacification between diabetics $(25 / 90,28 \%)$ and non-diabetics $(48 / 263,18 \%)$ (Mantel-Haenszel $p=0.32$ ).

Differences in the incidence of capsular opacification between groups were not explained by age when tested using Cox's proportional hazards modelling. No significant relationship between intraoperative and post-operative complications and posterior capsular opacification was identified.

\section{DISCUSSION}

This retrospective review reports a higher incidence of posterior capsule opacification in patients with either nonproliferative or quiescent proliferative diabetic retinopathy than in non-diabetics (Mantel-Haenszel $p=0.04$ ). Despite the slightly younger age of diabetic patients, Cox modelling did not identify age as a confounding factor in the detection of these differences. There are three possible explanations for the higher incidence of posterior capsular opacification in diabetic patients with retinopathy. Firstly, cataract surgery may be more complicated (e.g. the requirement for sphincterotomy), and secondly post-operative complications (e.g. persistent uveitis) are commoner in the diabetic than the non-diabetic eye. No relationship between capsular opacification and postoperative uveitis was, however, identified. A third possible explanation is that proliferation of lens epithelial cells may be promoted by forward diffusion of growth factors from ischaemic retina. Iris neovascularisation develops more commonly following intracapsular than extracapsular cataract extraction in diabetics, ${ }^{16}$ because the posterior capsule acts as a partial barrier to the forward diffusion of growth factors. Growth factors may therefore accumulate at the posterior capsule and promote migration, proliferation and differentiation of residual lens epithelial cells. The higher incidence of posterior capsular opacification in the quiescent proliferative retinopathy group, in which significant retinal ischaemia and therefore growth factors are present, is in accord with this hypothesis.

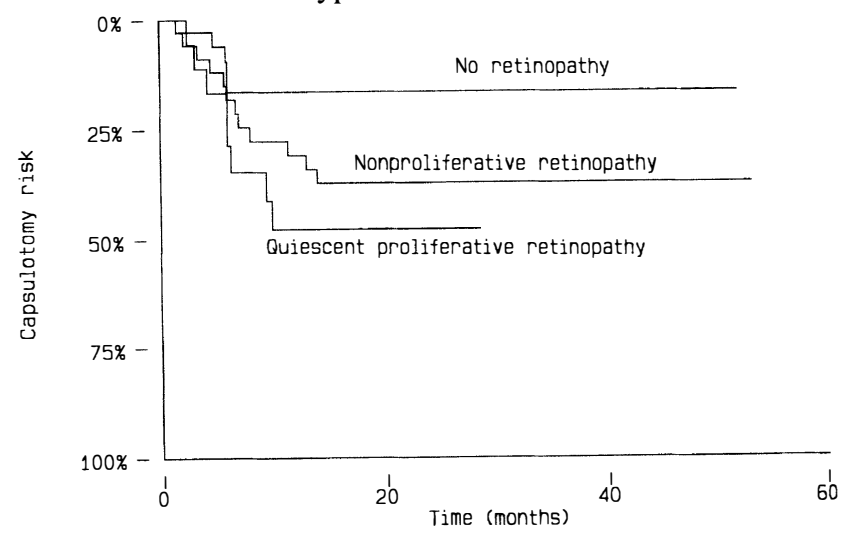

Fig. 2. Kaplan-Meier survival curve showing capsulotomy risk in different retinopathy subgroups. 
The incidence of posterior capsular opacification in diabetics and non-diabetics has previously been reported as $28 \%$ and $33 \%$ respectively in a retrospective review of 939 eyes including 202 diabetics followed for a mean of 26 months. The lower incidence of posterior capsular opacification was explained by reduced lens epithelial cell proliferation due to intracellular accumulation of sorbitol. These findings are in contrast to the results of this study and may be explained by the different statistical method employed. In this study, Kaplan-Meier survival analysis was used to allow for variation in follow-up. It is recognised that diabetic patients may have undergone posterior capsulotomy with less opacification than non-diabetics in order to maintain fundus visualisation. Conversely, diabetics with maculopathy may not be aware of visual loss due to capsular opacification, suggesting that the incidence of capsular opacification might be higher than reported. A prospective trial of the incidence of posterior capsule opacification is required to address this.

The practical implications of this study are that posterior capsule opacification is a common occurrence after extracapsular cataract surgery in all patients, but is more common in diabetics with non-proliferative or quiescent proliferative retinopathy. It is therefore important to keep these patients under careful review so that a large posterior capsulotomy can be performed with Nd:YAG laser at the earliest opportunity to maintain adequate fundus visualisation and assessment of diabetic retinopathy, which is particularly likely to deteriorate after cataract extraction. Early posterior capsulotomy is important in patients with pre-existing retinopathy, since they are at the greatest risk of both posterior capsule opacification and post-operative deterioration of retinopathy.

Key words: Cataract extraction, Diabetic cataract. Diabetic retinopathy, Nd:YAG posterior capsulotomy, Posterior capsule opacification.

\section{REFERENCES}

1. Percival SPB, Anand V, Das SK. Prevalence of aphakic retinal detachment. Br J Ophthalmol 1983;67:43.

2. The Miami Study Group. Cystoid macular oedema in aphakic and pseudophakic eyes. Am J Ophthalmol 1979;88: 45.

3. Nishi O. Incidence of posterior capsular thickening in eyes with and without posterior chamber intraocular lenses. J Cataract Refract Surg 1986;12:519-22.

4. Maltzmann BA, Haupt E, Notis C. Relationship between age at time of cataract extraction and time interval before capsulotomy for opacification. Ophthalmic Surg 1989;20: $321-4$.

5. Kraff MC, Sanders DR, Lichman HL. Total cataract extraction through a $3 \mathrm{~mm}$ incision: report of 650 cases. Ophthalmic Surg 1979; 10:46-54.

6. Wilhelmus KR, Emery JM. Posterior capsular opacification following phacoemulsification. Ophthalmic Surg 1980;11: 264-7.

7. Solomon KD, Legler UFC, Kostick AMP. Capsular opacification after cataract surgery. Curr Opin Ophthalmol 1992; $3: 46-51$.

8. Ohadi C, Moreira H, McDonnell PJ. Posterior capsule opacification. Curr Opin Ophthalmol 1991;2:46-52.

9. McDonnell PJ, Zarbin MA, Green R. Posterior capsule opacification in pseudophakic eyes. Ophthalmology 1983; 90:1548-53.

10. Benson WE. Cataract surgery and diabetic retinopathy. Curr Opin Ophthalmol 1992;3:396-400.

11. Krupsky S, Zalish M, Oliver M, Pollack A. Anterior segment complications in diabetic patients following extracapsular cataract extraction and posterior chamber intraocular lens implantation. Ophthalmic Surg 1991;22:526-30.

12. Hykin PG, Stevens JD, Gregson RMC, Hamilton AMP. Extracapsular cataract extraction in proliferative diabetic retinopathy. Ophthalmology 1993;100:3-11.

13. Hykin PG, Gregson RMC, Hamilton AMP. Extracapsular cataract extraction in diabetics with rubeosis iridis. Eye 1992;6:296-9.

14. Cunliffe IA, Flanagan DW, George NDL, et al. Extracapsular cataract surgery with lens implantation in diabetics with and without proliferative retinopathy. $\mathrm{Br} \mathrm{J}$ Ophthalmol 1991;75:9-12.

15. Knorz MC, Soltau JB, Seiberth V, Lorger C. Incidence of posterior capsule opacification after extracapsular cataract extraction in diabetic patients. Metab Pediatr Syst Ophthalmol 1991;14:35-6.

16. Poliner LS, Christianson DJ, Escoffery RF, et al. Neovascular glaucoma after intracapsular and extracapsular cataract extraction in diabetic patients. Am J Ophthalmol 1985; 100:637-43. 